\title{
STUDENT PRACTICES IN USE OF LECTURE RECORDINGS IN TWO FIRST-YEAR COURSES: POINTERS FOR TEACHING AND LEARNING
}

\author{
V. Frith* \\ e-mail: vera.frith@uct.ac.za

\section{P. Lloyd ${ }^{*}$} \\ e-mail: pamela.llovd@uct.ac.za
}

\author{
*Academic Development Programme \\ University of Cape Town \\ Cape Town, South Africa
}

\section{ABSTRACT}

Although there is a large body of research that exists internationally about how students use lecture recordings, it is necessary to consider the South African situation, where a large proportion of students entering higher education are underprepared and for whom English is not their first language. This study investigated student use of lecture recordings in two different first-year courses, one a standard mathematics course and the other a quantitative literacy course using a lecture-workshop mode of delivery. The results from this study confirm much of what has been seen internationally, that is, that students value the availability of lecture recordings and perceive that their learning is improved by having access to them. Lecture recordings are used mainly to make up for missed lectures, but also to review material from lectures and improve notes made in lectures. There is also evidence of increased usage of recordings immediately prior to assessments. This study found no evidence of a relationship between lecture attendance and recording usage. It also revealed that the extent of use of lecture recordings differs in different course contexts, and that students with lower academic English competence make significantly greater use of the recordings. Limitations that became apparent due to reliability of data obtained by different methods (from questionnaires and from the learning management system) are discussed. Finally, recommendations are made for classroom practice that could enhance academically immature students' use of lecture recordings as a valuable learning resource.

Keywords: lecture recordings, student learning, lecture attendance, student attitudes

\section{INTRODUCTION}

In line with trends internationally, the video recording of lectures has recently become the norm at our university. The recordings are produced automatically (unless lecturers choose to "opt out") by the recording equipment installed in most lecture theatres and are made available to 
students via the online learning management system. There has been pressure from students to make recordings widely available, but lecturers in general do not have a clear understanding of how students use them. Understanding student practices is a necessary prerequisite for lecturers to understand how these practices can contribute to their teaching and for being able to advise students on how to make the best use of lecture recordings for meaningful learning.

Although there is a large body of research that has been conducted internationally on how students use lecture recordings, there is less research that has been done recently in South Africa, particularly involving the large proportion of students entering higher education who are underprepared and for whom English is not their first language. In this study we investigated the use of lecture recordings in two different first-year courses, a quantitative literacy course for law students and a mathematics course for engineering students. By comparing the influence of the different teaching and learning contexts of the two cohorts on the ways that they use lecture recordings, we hope to provide insights into the complicated relationship between course context and recording usage, but also to highlight what may be generalised across courses.

As pointed out by Nordmann and McGeorge $(2018,1)$, there is a need to move away from the "binary question of whether or not lecture capture should be used" and focus rather on the role it should play in teaching and learning. Our research questions have thus been centred on some aspects of teaching and learning. We investigated the learning support role that may be played by lecture recordings by ascertaining students' attitudes to the availability of lecture recordings and how, why, when and how much they use them.

There is concern among lecturers that having lecture recordings available may encourage students not to attend lectures and thus this relationship was examined. Unlike most of the studies in the literature, we did not rely on student self-reported attendance data, but used attendance registers. In addition, we explored whether students with lower levels of English language competence use lecture recordings more. Our approach to addressing this question differed from what has been done previously, in that we used the score obtained by each student on the academic literacy (AL) component of the National Benchmark Test (NBT) as a measure of language competence. We also investigated whether there is an association between the use of recordings and performance. Finding answers to questions like these will help us to better understand the role of lecture recordings in teaching and learning in university courses and to design ways to support students in using them efficiently and productively. We discuss ways to improve teaching and learning in the context of lecture recording availability by assisting students to recognise what this technology offers for the enhancement of their learning and how best to use it. 
Ethics approval for this study was obtained from the relevant faculty research ethics committees and from the student affairs department at our university. This process included the approval of our questionnaire and of our procedure for obtaining informed consent from students.

\section{LITERATURE REVIEW}

Over the past twenty years, numerous papers have been published reporting on studies of the use of podcasts and video recordings of lectures in university courses in a range of different disciplines and contexts. These have been extensively reviewed, with several review papers having been published since 2012 (Nordmann and McGeorge 2018; O'Callaghan et al. 2017; Witthaus and Robinson 2015; Karnad 2013; Kay 2012). A study published by Draper, Gibbon and Thomas (2018) also includes an extensive literature review. So to provide the background for this present study we need only briefly summarise what these review papers, especially the most recent ones, have to say about issues relevant to our research questions.

With regard to student attitude towards availability of lecture recordings "studies have shown consistently that students value having access to and make use of recordings of lectures" (Nordmann and McGeorge 2018, 7). These authors also report that recording availability has been shown to reduce students' anxiety and suggest it may be because recordings offer the opportunity for students to self-regulate learning.

The extent of use of recordings varies immensely with the context, ranging from far below 50 per cent of students to almost 100 per cent who report using them in a particular course (Witthaus and Robinson 2015, 9), but also, among users the level of use varies for different kinds of students. Similarly, the ways that students use recordings and their reasons for using them vary greatly with the course context and between different students. Witthaus and Robinson $(2015,9)$ report that, according to the literature they reviewed, the majority of students claimed they used lecture recordings "as a supplement to, not a replacement for, live lectures".

There is evidence that recordings are used more by students learning in a second language (Nordmann et al. 2019, 12; Nordmann and McGeorge 2018, 10; O'Callaghan et al. 2017, 405; Mallinson and Baumann 2015, 480; Collier-Reed, Case and Stott 2013, 337) because access to recordings allows these students to overcome language difficulties experienced during the live lecture.

Contradictory evidence regarding the effect of lecture recordings on attendance is obtained from different studies in different contexts, but "The balance of research suggests that having access to lecture recordings has either no or only a very small impact on attendance" (Nordmann 
and McGeorge 2018,6). Similarly, contradictory evidence is reported regarding a possible relationship between lecture recording viewing and student performance, given that there are many other interacting variables that all also impact on performance, such as levels of lecture attendance, student ability and effort, manner in which recordings are used and how frequently they are accessed. In their review, Nordmann and McGeorge $(2018,13)$ pointed out that whether the evidence for the positive role of lecture recordings is consistent "appears dependent on a mix of student characteristics, the nature of the material, and the way the recordings are used". They also stressed that

"perhaps the more appropriate question here is not, do students as a whole benefit from access to recordings of lectures, but why do some benefit and others not? What does this tell us about pedagogy and how people learn, and what can we tell students about how to maximise the value of this type of resource?" $(2018,12)$.

Dunlosky et al. $(2013,35)$ report that consistent "distributed practice" has been found to lead to more effective learning than cramming before assessments. For this reason, it becomes useful to understand students' practices in terms of when during the semester they make the most use of lecture recordings as a learning resource. Nordmann and McGeorge $(2018,19)$ suggest that the ready availability of lecture recordings provides the potential for students to cram instead of using the recordings consistently throughout the semester. In an earlier study Collier-Reed, Case and Stott $(2013,336)$ found that in an engineering course almost half of all lecture recording downloads occurred in the two-week period before the examination. Similarly, a study of microeconomics students (Chen and Lin 2012,13) established that, of the students who used lecture recordings, most accessed the recordings immediately before an assessment, rather than soon after lectures.

Some implications of the literature for our study are as follows. Because student use of lecture recordings varies so much with the context it is not possible to depend solely on the literature to gain an understanding of how one's own students use recordings. For the same reason, making a comparison between how students in two different courses use recordings can be instructive. The reviews point out that most research has used student self-reported data on attendance (O'Callaghan et al. 2017, 405), which presumably is not particularly reliable or accurate. We used class attendance registers and card scanning records in this study in the hope of obtaining a more reliable measure. Clearly it is important in the South African context to know if lecture recordings can mitigate language difficulties for students for whom the language of instruction is not their home language. As suggested by Nordmann et al. $(2019,28)$, with data analytics now being more readily provided by learning management systems, it would be useful to ascertain whether students distribute their use of the recordings across the semester or 
whether they tend to concentrate their usage before assessments.

\section{METHODS}

The students we studied were doing different courses, the one being a mathematics course for engineering students and the other a quantitative literacy course for first-year law students. The former is a standard course with a focus on calculus and linear algebra concepts that are directly applicable to engineering problems. It is a repeat of a first-year course, so the engineering students were in their second year at university. The quantitative literacy course aims to develop the ability of first-year students to reason about quantitative information by applying elementary mathematical and statistical knowledge learned at school to a broad range of law-related and real-world contexts. Due to the differences in their content and nature, the mathematics course might be considered to be one that is focused upon "knowledge acquisition and facts" whereas the quantitative literacy course, albeit a first-year course, requires "deeper critical thinking skills and the application of knowledge" (Nordmann and McGeorge 2018, 14).

In the quantitative literacy course the lectures were run as lecture-workshops where, as well as receiving a mini-lecture explaining concepts using a Powerpoint presentation, the students had an opportunity to engage, together with other students, with the application of the concepts in context and request attention from the lecturer when needed. The pace in this course is therefore slower than in courses where full lectures are given. The quantitative literacy students had access to the detailed, animated Powerpoint presentations that were made in the lectures as well as the video recordings. In the mathematics course the material was presented in lecture-format with no accompanying Powerpoint slides and for these students the video was the only record of the lecture (other than their own notes) that was available.

Data was collected twice in the semester. Two-thirds of the way through the semester a paper-based survey of all students in the two courses was undertaken and data regarding students' use of the video recordings was obtained from the learning management system. After the final exams were written the data analytics from the learning management system were again obtained. Data regarding lecture attendance was obtained at both times.

The paper-based questionnaire was designed to obtain student self-reported data for the research questions relating to attitudes to recordings, reasons for, extent and manner of use, and perceived effect of lecture availability on attendance. It was administered to the quantitative literacy students during lectures and to the mathematics students in tutorials. In both cases there was about a two-thirds response rate, with 54 and 65 responses respectively. The questions were mostly Likert-style questions with four alternatives such as "Strongly agree, Agree, Disagree, Strongly disagree" or "Always, Often, Occasionally, Never". For many questions, students 
were also invited to explain their answers in an open-ended way. For the first few questionnaire items that all respondents were asked to complete, the distributions of responses were calculated as percentage frequencies of total number of respondents. Later questions about reasons for and manner of usage were directed only at those students who had viewed all or part of three or more recordings (whom we called "users") and in this case the frequencies were calculated as percentages of the total number of users.

For an independent measure of the extent of usage we used data available from the learning management system. We extracted the total number of different recordings opened by each student (which we will call "unique views"). Unfortunately, one cannot say if this is the total number of recordings that a student actually watched, and it is in fact likely to be an overestimate, because students may open several videos while searching for a particular concept they are wanting to review. This measure excludes possible repeated viewings of the same video but does provide an indication of a student's level of activity with regard to accessing the recordings. At the survey stage we further categorised users according to whether they had more than ten unique views (we called these students "heavy users") or ten or fewer views.

At the end of the semester, because the number of lectures had increased, the definitions of users and heavy users were redefined to be students who had viewed more than one-fifth and more than half of the available recordings, respectively.

The lecture attendance was recorded for each student in each lecture. In the quantitative literacy course students were required to sign a register, as a small amount of course credit was given for attendance. The mathematics students recorded their attendance using a card-scanning device in the lecture theatre. They were also offered a small incentive in terms of bonus marks for attendance. From these records we could calculate a percentage attendance value for each student. Simple linear regression analysis was carried out to investigate the relationship between percentage attendance and number of unique views.

For the question relating to extent of use of recordings by students with lower English competence we used the score obtained by each student on the academic literacy (AL) component of the National Benchmark Test (NBT) as a measure of language competence. This test is part of a suite of tests written by university applicants that is intended to provide a measure of their readiness for university study (Griesel 2006) and assesses their competence in terms of cognitive academic language proficiency (Cummins 1999). The students' scores were classified into two groups based on whether they were regarded as "proficient" (which is defined as an NBT AL score greater than $68 \%$ ) or not. Chi-squared testing was used to establish the degree of statistical significance of the relationship between heavy lecture recording use and NBT AL score category. 
In order to examine any potential relationship between lecture recording usage and performance, students were divided into two performance categories; those whose course mark was above the median mark and those whose mark was below the median. As before, chisquared testing was used to establish the degree of statistical significance of the relationship between heavy lecture recording use and performance category.

To get a sense of frequency and timing of overall use of lecture recordings throughout the semester, we made use of the complete set of viewing data as supplied by the learning management system; in other words, we examined the distribution of all views made by students, not just unique views, across the whole semester.

\section{RESULTS}

\section{What are students' attitudes to lecture recordings?}

Almost all of the respondents to the survey in the two courses agreed that they liked the fact that lecture recordings were available (quantitative literacy: 89\%, mathematics: 100\%); an example of a student comment reflecting this view being

"I think having lecture videos is very effective even though I don't use them as much because sometimes lecturers go too fast in class and you're confused but scared to lift your hand and ask so when you watch the lecture videos, you can pause it and rewind to ensure you grasp the concept and can simultaneously read printed notes."

However, only just over a quarter (28\%) of the students in the quantitative literacy course said they had watched all or part of three or more recordings (i.e. were users). All of these students agreed that "having the recordings has improved my learning in this course". In contrast, students in the mathematics course made much more use of the recordings, with almost 70 per cent being users. Of these, 89 per cent believed that the recordings had improved their learning. Thus, overall, the attitude towards the usefulness of the recordings as a learning tool was generally more positive among the students in the mathematics course.

\section{Extent of use of recordings}

Figure 1 shows the distribution of the numbers of recordings users claimed to have watched (from data obtained from responses to the questionnaire). In the quantitative literacy course, a large proportion of the users (who were $28 \%$ of the respondents) claimed to have watched only three or four recordings, but in the mathematics course a similar proportion of the users (who were $70 \%$ of respondents) watched 16 or more. 


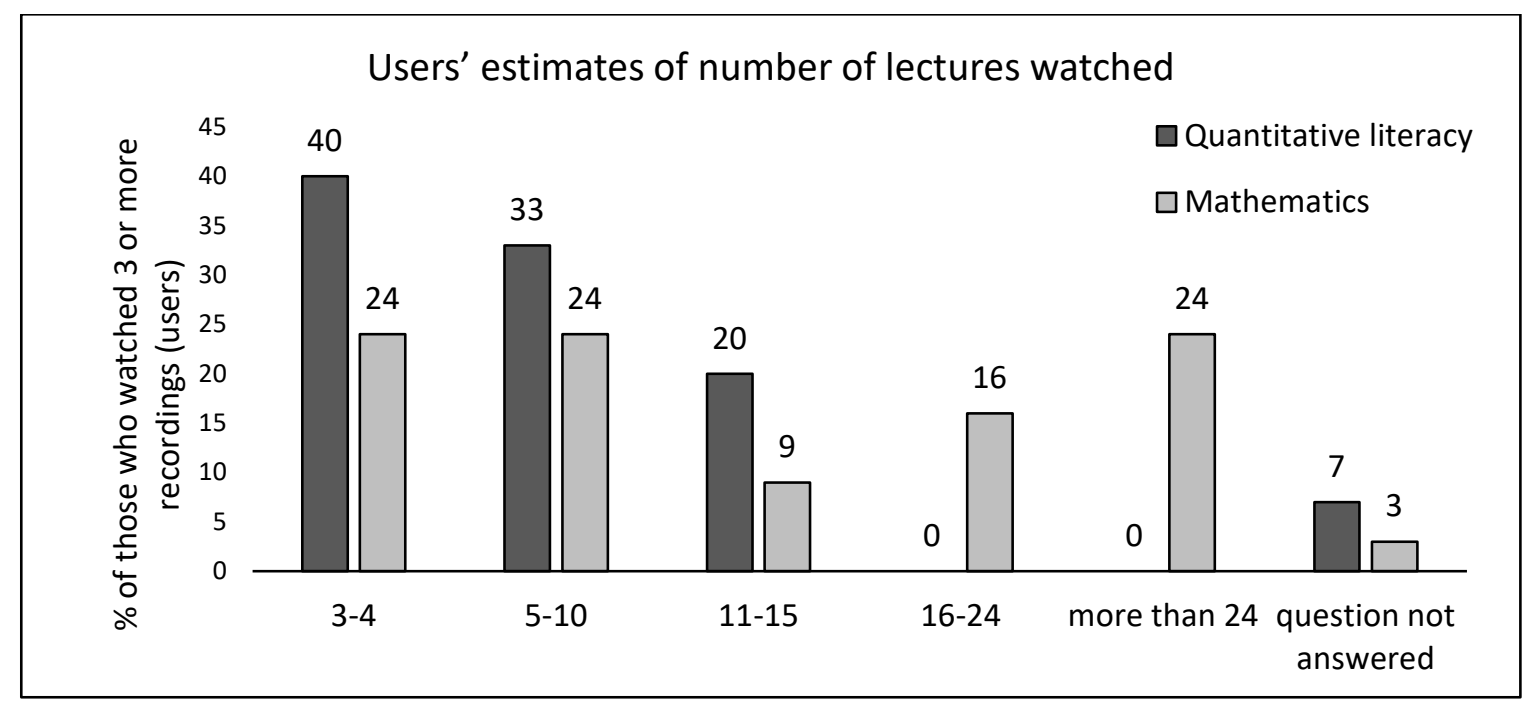

Figure 1: Student users' estimates of the number of lectures for which they watched the whole or part of the recording (excluding those who claimed to have watched fewer than three recordings)

Of all the respondents (not just the users) in the quantitative literacy course only 6 per cent claimed to have watched more than 10 recordings while a third of the mathematics students had watched more than 10 recordings.

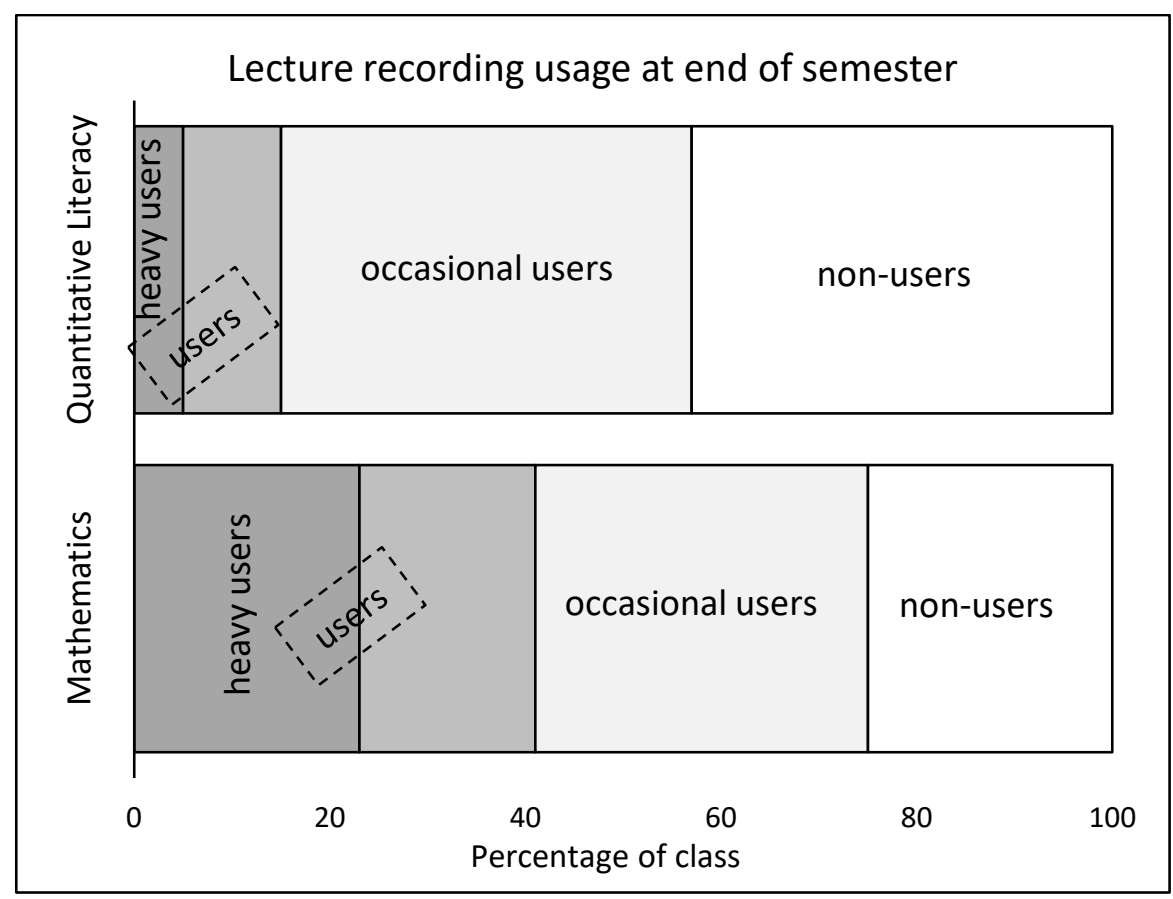

Figure 2: Levels of usage of lecture recordings in the quantitative literacy and mathematics courses at the end of the semester

Data obtained from the learning management system showed that by the end of the semester there had been a notable increase in the proportion of the quantitative literacy students who made any use of the lecture recordings - from 35 per cent of the class at the time of the survey to 57 per cent of the class at the end of the semester. The use by mathematics students in this period increased slightly from 70 per cent of the class to 75 per cent of the class. Nonetheless, 
Figure 2 shows that at the end of the semester a far greater proportion of the mathematics students were users (viewed more than one-fifth of the recordings) and heavy users (viewed more than half of the recordings) than were the quantitative literacy students.

Finally, the learning management system data allowed for viewing rates to be calculated and these confirm the overall greater usage levels of the recordings in the mathematics course. The quantitative literacy students viewed, on average, three lecture recordings $(9 \%$ of the 33 recordings) in the semester, whereas the mathematics students viewed, on average, 14 lecture recordings ( $25 \%$ of the recordings). These rates support the findings of Danielson et al. (2014, $125)$, who concluded that students are significantly more likely to view lecture recordings when the lecture is a "straight lecture" than when it is a "mixed lecture/group work" session.

\section{Why and how do students use the recordings?}

In the questionnaire we asked the users to rank their three main reasons for using recordings and the results are shown in Figure 3. The most popular first choice was to make up for lectures
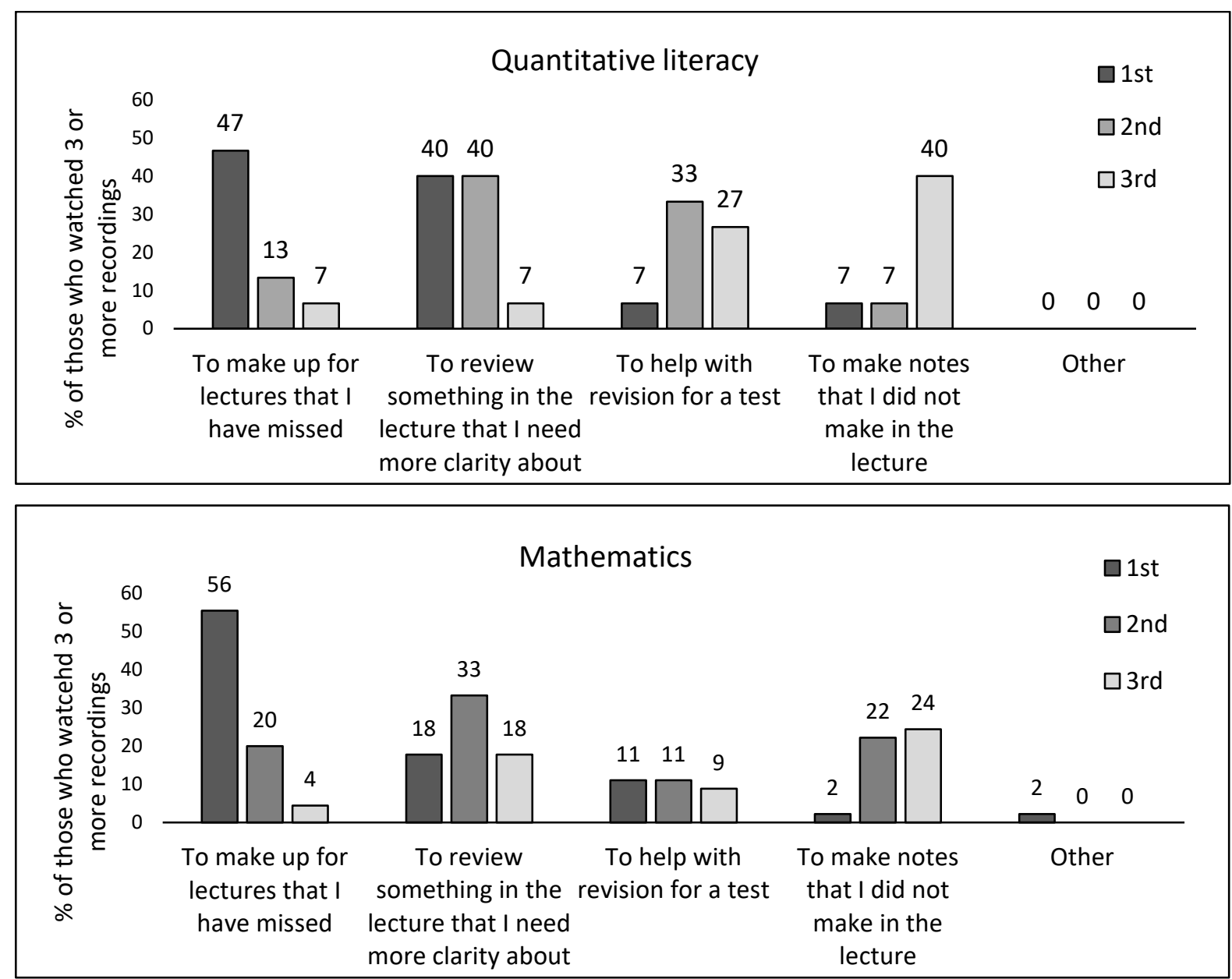

Figure 3: Users' three main reasons for using lecture recordings, ranked in order of importance 
missed: in both courses approximately half of the users' main reason for watching recordings was to make up for lectures not attended. The most popular second choice was to review material from the lectures attended and the most popular third choice was to improve their lecture notes. This use of the recordings is described well by the student who wrote: "I can pause/play and fast forward at the pace in which I am understanding. And I frequently need to replay certain parts for clarity or pause so that I can take down notes without missing anything."

Figure 4 shows that students in both courses who had attended a particular lecture most frequently tended to watch only parts of the recording and only occasionally watched the entire recording.
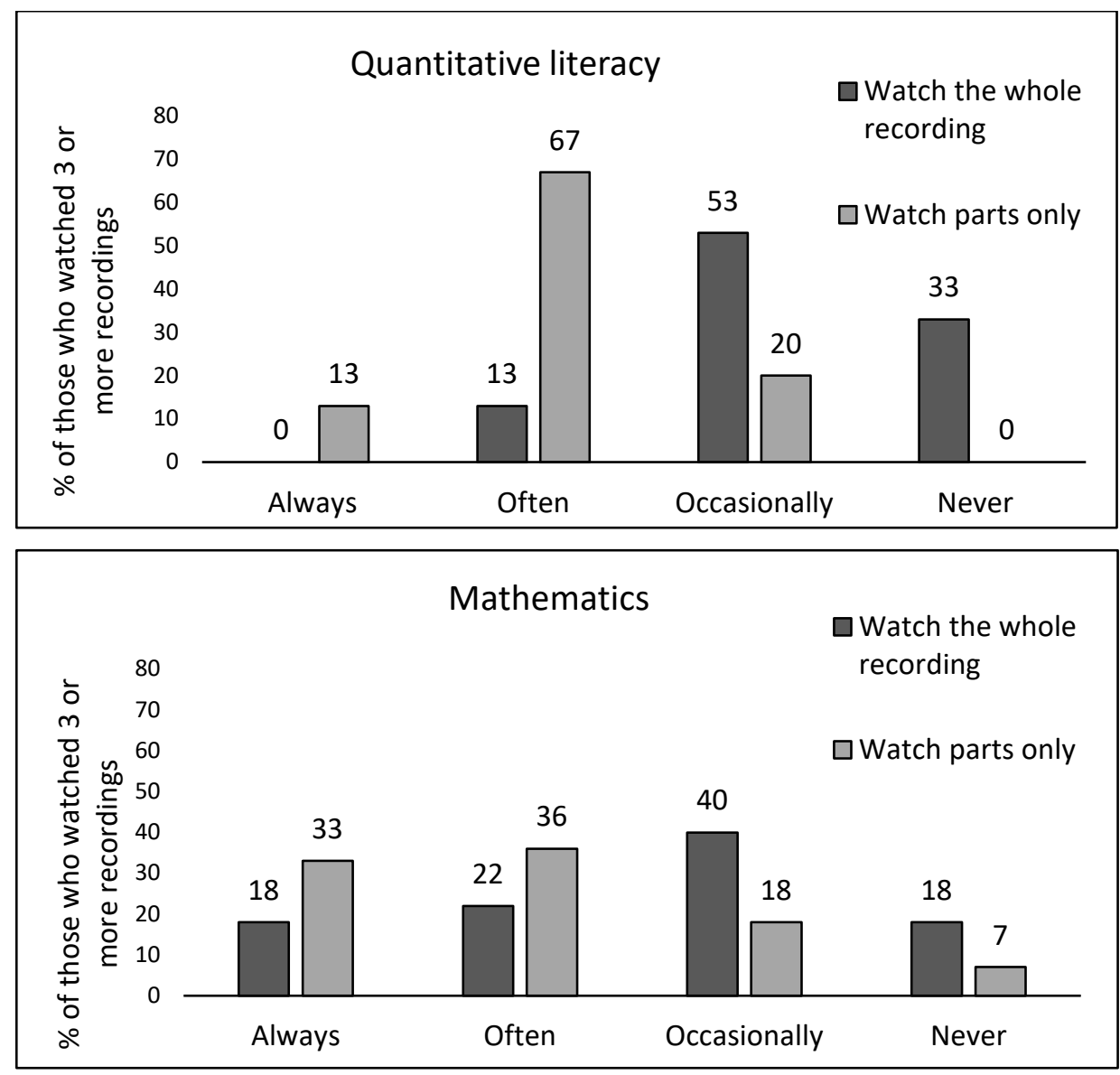

Figure 4: Users' responses to questions about the frequency of watching the entire recording or parts of the recording when viewing a recording of a lecture that they had attended

Figure 5 shows the responses to a question asking users to say how frequently they planned to watch and how frequently they in fact did watch recordings of lectures that they had not attended. Not surprisingly, in both courses when students missed a lecture they often planned to watch the recording, but less often got around to doing so, although the mathematics students were more likely to view the recording of a missed lecture. 

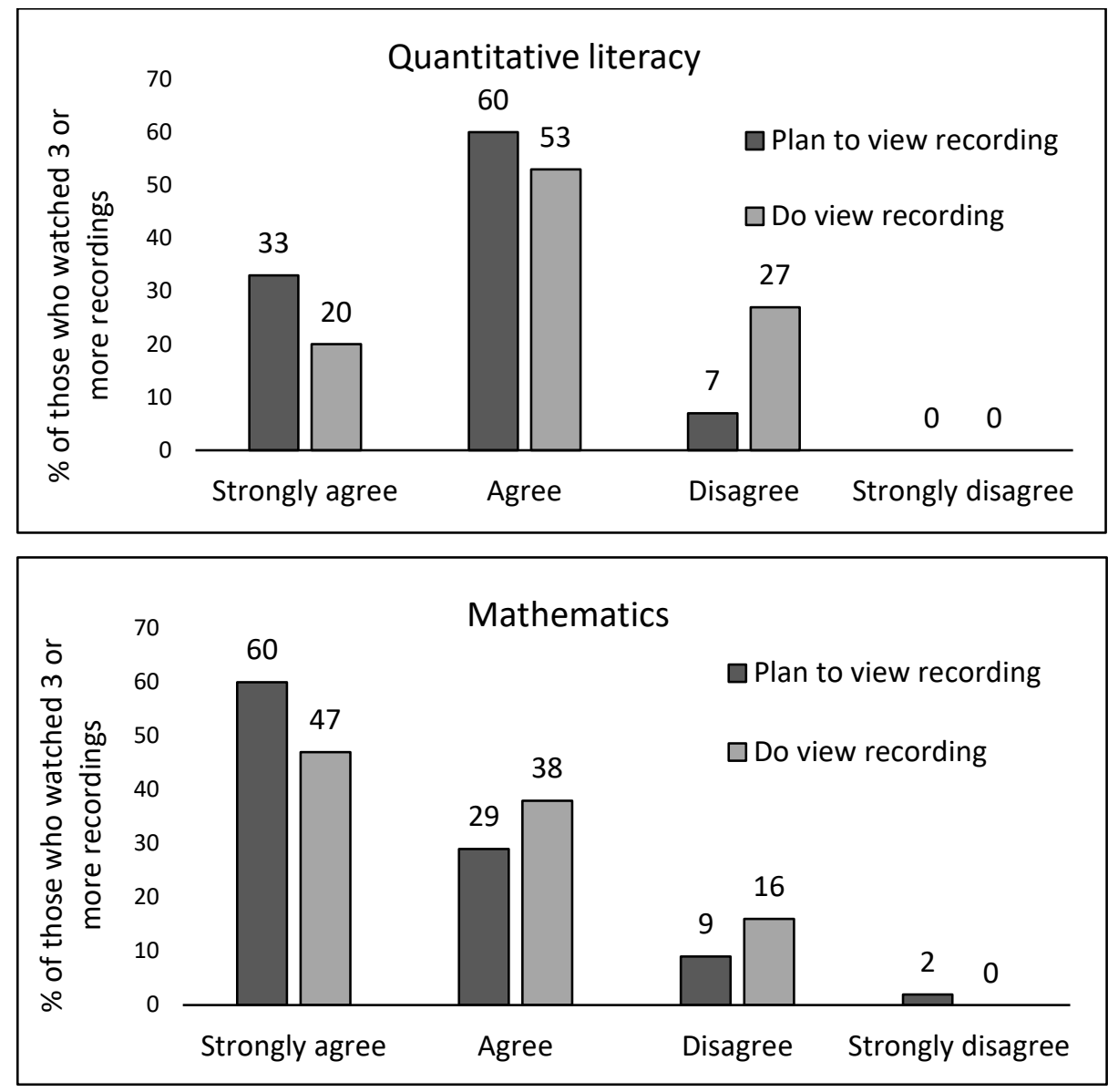

Figure 5: Users' responses to the statements "If I miss a lecture I always plan to view the recording" and "If I miss a lecture I always do view the recording"

Figure 6 shows the frequency of different kinds of behaviour reported by users when watching the recording of a lecture they had missed. It shows that mostly they make notes and watch the entire recording. As might be expected, this is different from what was reported regarding watching videos of lectures attended, when users reported mostly watching only parts of the video.

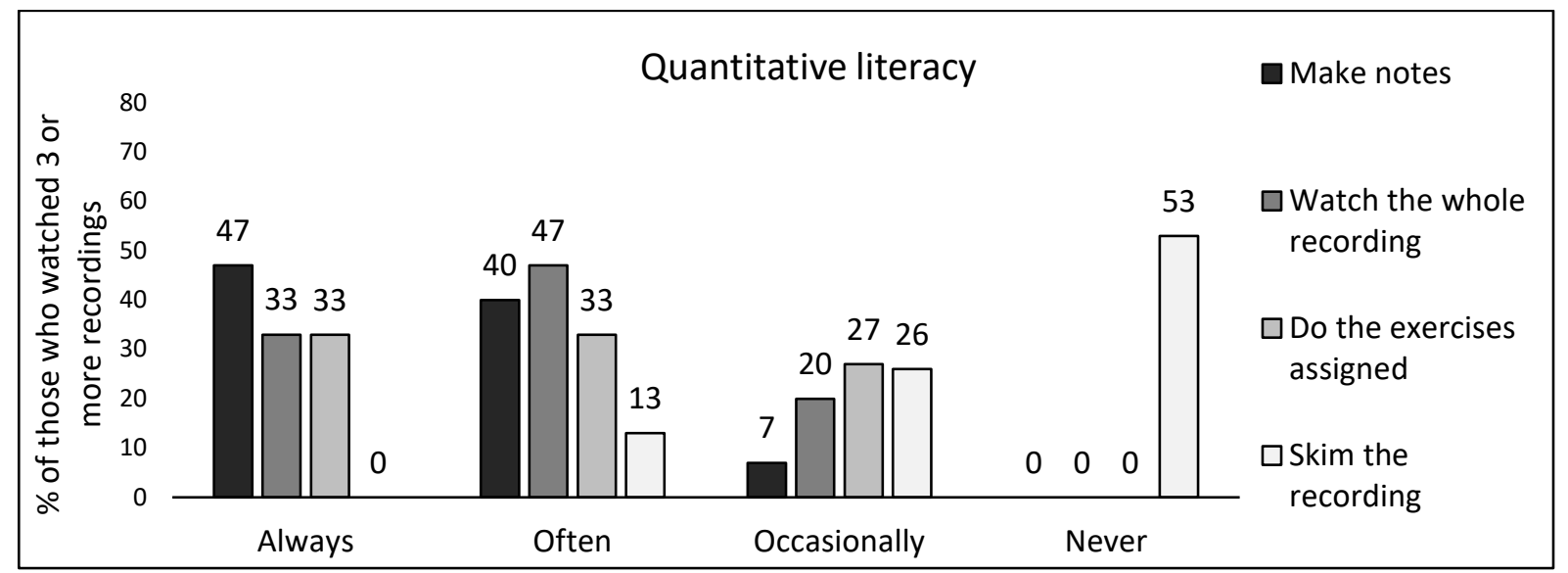




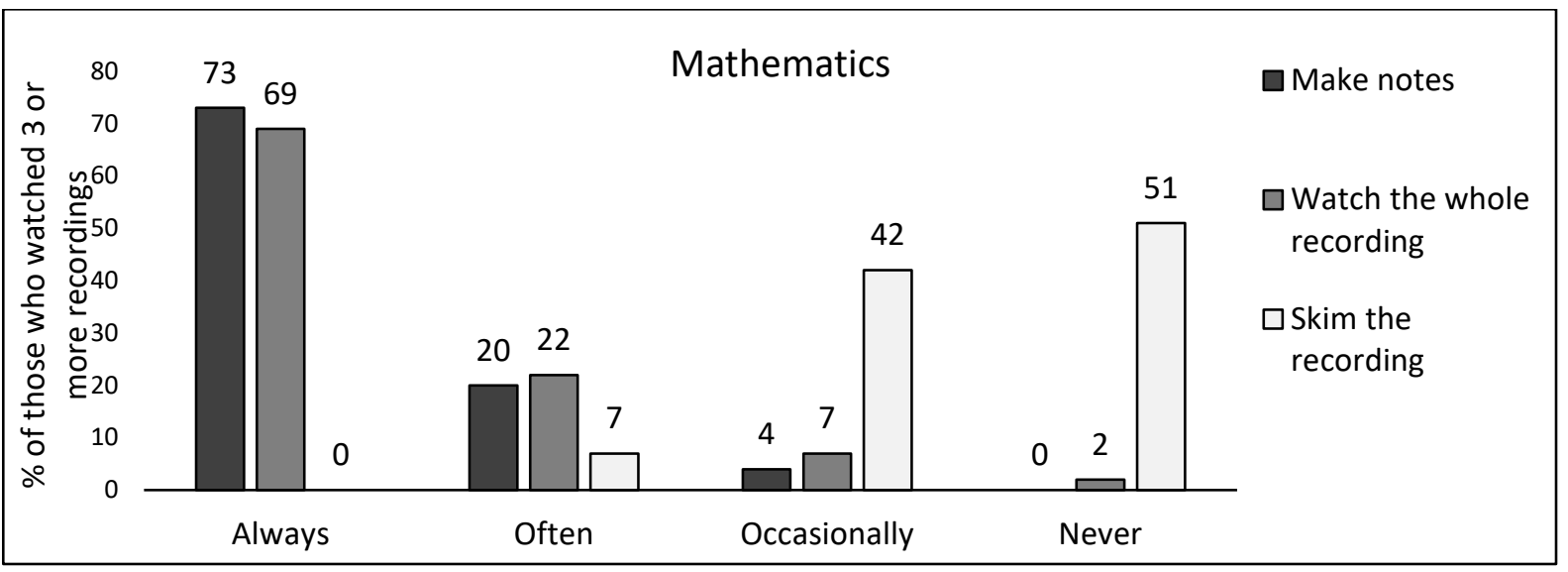

Figure 6: Frequency of different kinds of behaviour reported by users when watching the recording of a lecture they had missed

It is noteworthy that in the quantitative literacy course two thirds of the users said that they always or often did the exercises at the point in the recording where the class was required to do them. This is a sensible learning practice because subsequent parts of the video would usually contain an explanation of these exercises. (While assigning exercises for students to do in class was a regular feature of the quantitative literacy lectures, this practice was not a significant component of the mathematics course lectures.)

\section{Effect on attendance}

Figure 7 shows the frequency of responses to the statement "Knowing that there is a recording makes it easier for me to decide not to attend the lecture". A fairly substantial proportion of users, particularly in the mathematics course, agreed with this statement. This suggests a negative effect of the recordings on attendance but is merely an indication of a possibility based on student self-reported data.

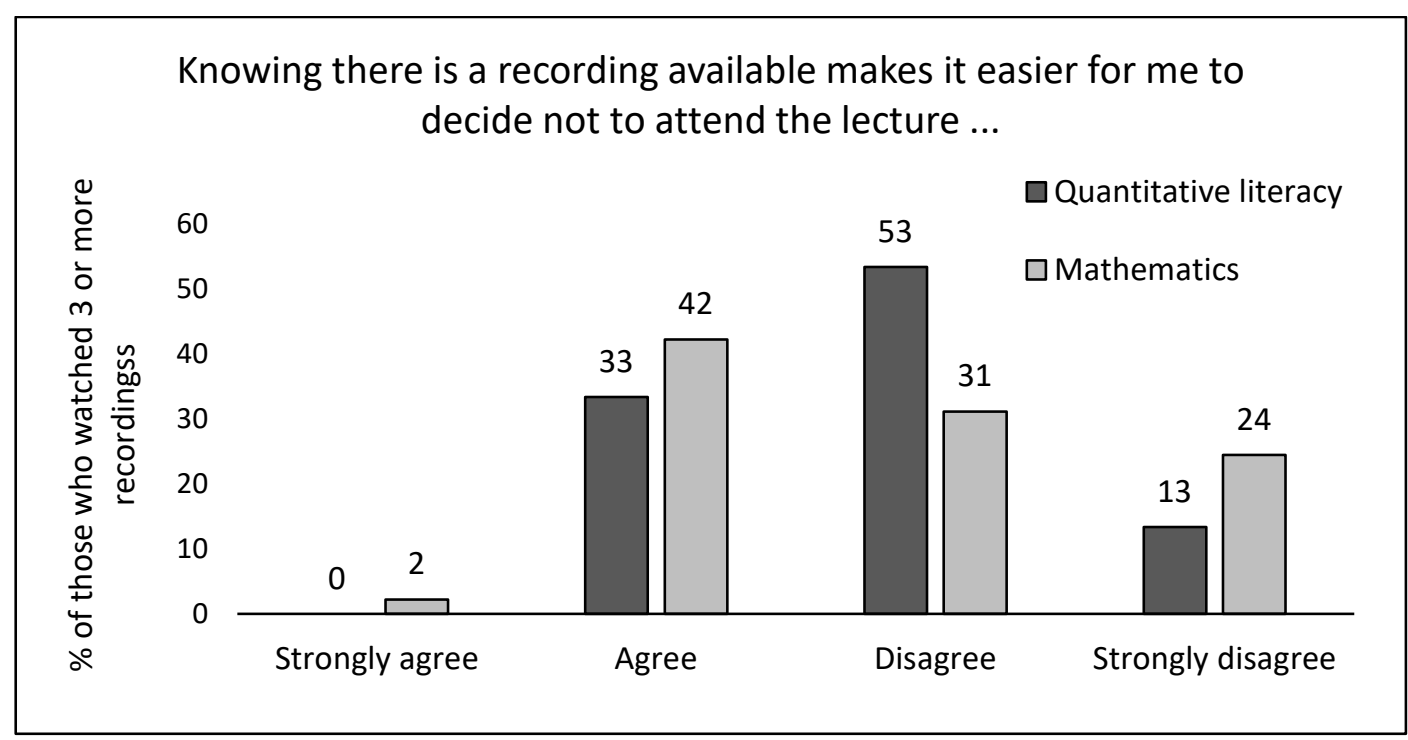

Figure 7: Responses to the statement "Knowing there is a recording available makes it easier for me to decide not to attend the lecture" 
In order to investigate whether recordings have an effect on attendance without depending on students' self-reported data, we used the attendance records and the "unique views" data from the learning management system. These data can be correlated because in both cases the values are recorded for each individual student. The scatter plots in Figure 8 use data for the entire semester and show that we were unable to demonstrate that a relationship exists between these two sets of data. There is not enough evidence to conclude that, in general, students who attend less are using the recordings more, which confirms results found by other researchers mentioned in the literature section above.

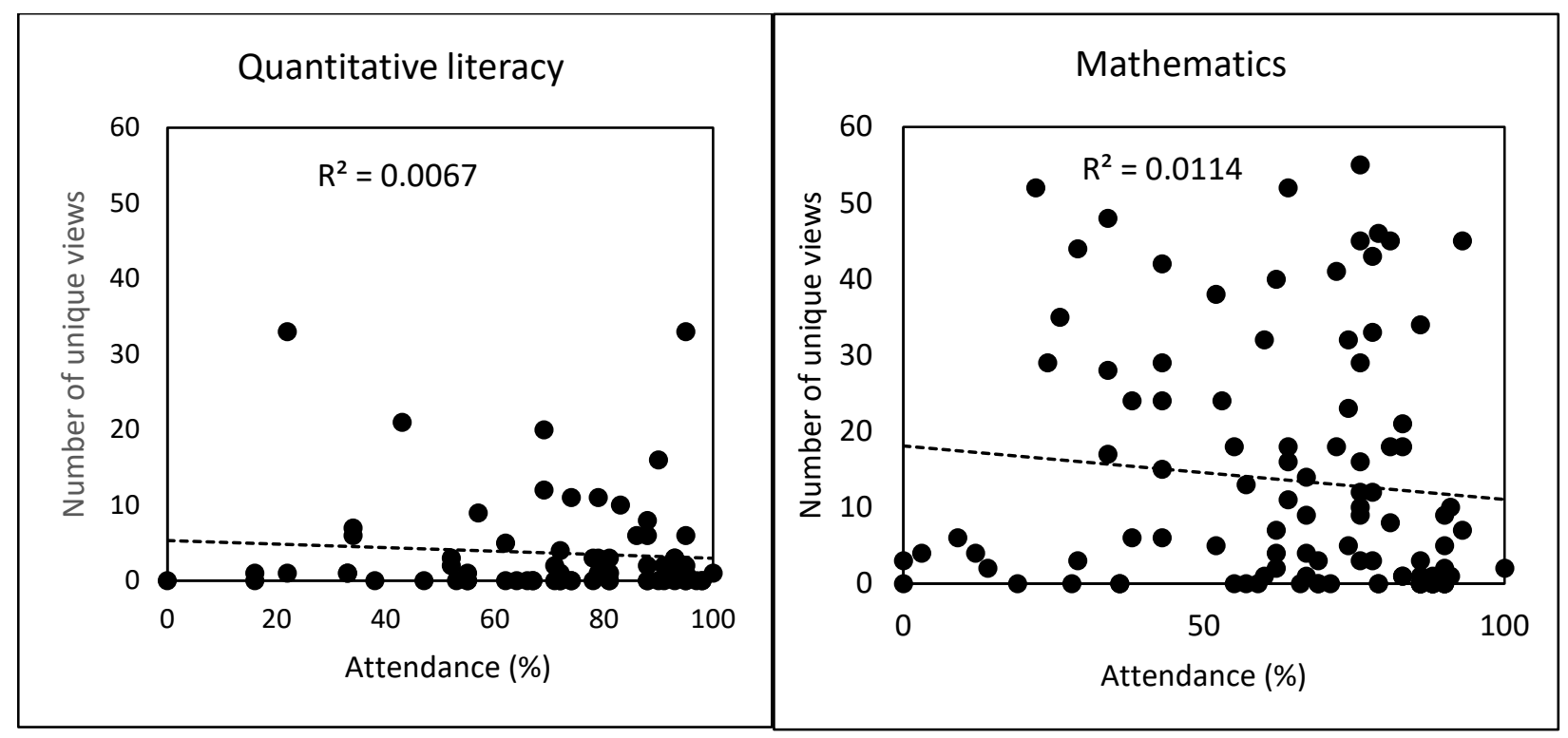

Figure 8: Relationship between attendance and lecture recording views using data for the entire semester

\section{Are recordings used more by students with lower levels of English language competence?}

There is some evidence in the literature that students for whom English is not their first language use recordings more frequently in order to compensate for difficulty in understanding the lecturer. Nordmann et al. $(2019,12)$ found that non-native speakers used lecture recordings significantly more than native speakers. It is clearly relevant to establish if this is the case in a South African context, because it should have implications for policies regarding lecture recording usage in an environment where significant numbers of students are "secondlanguage" English speakers. Collier-Reed, Case and Stott $(2013,337)$ found some evidence for greater use of lecture recordings by second-language students in interviews with a group of second- and third-year South African engineering students. We wished to canvass all of the students in our study on this issue and specifically asked about whether students regarded 
themselves as second-language speakers of English. However, we were not successful in formulating a question in the questionnaire that identified these students reliably enough to our satisfaction, so we used NBT academic literacy results as a measure of students' language proficiency and explored whether there is a relationship between lecture recording users' NBT AL scores and their frequency of use of recordings (measured by the number of unique views).

This analysis, carried out at the time of the survey and then later at the end of the semester, was only done for the students in the mathematics course because there were not enough users in the quantitative literacy course to justify it statistically. We divided all the students in the mathematics course into two groups based on whether they were regarded as "proficient" in academic literacy (which is defined as an NBT AL score greater than $68 \%$ ) or not. We also divided them according to whether they were heavy users or not.

Table 1 shows that, at the time of the survey, 12 per cent (6) of the 49 students with NBT AL scores in the "proficient" category were heavy users, while a much greater percentage of the "not proficient" category, 43 per cent (22 of the 51), were heavy users. A chi-squared test confirmed that there is a highly significant association $(p=0.0006)$ between heavy use of recordings and having a NBT AL score that is lower than "proficient". The analysis was repeated at the end of the semester. Although the proportion of the 51 students with NBT AL scores below 68 per cent who were heavy users had decreased to 33 per cent, the association was still significant $(\mathrm{p}=0.03)$. This provides some evidence (albeit from only one course context) that students with lower English language competence make greater use of the recordings.

Table 1: Numbers of students in the mathematics course categorised according to academic literacy proficiency and lecture recording use at the time of the survey and at the end of the semester

\begin{tabular}{|c|c|c|c|c|c|}
\hline & \multicolumn{2}{|c|}{ NBT AL score } & \multirow[b]{2}{*}{ Totals } \\
\hline & & & Proficient & Not Proficient & \\
\hline \multirow{6}{*}{ 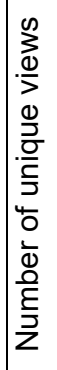 } & \multirow[t]{3}{*}{ at time of survey } & 10 or fewer & 43 & 29 & 72 \\
\hline & & More than 10 (heavy users) & 6 & 22 & 28 \\
\hline & & Totals & 49 & 51 & 100 \\
\hline & \multirow[t]{3}{*}{ at end of semester } & 27 or fewer & 42 & 34 & 76 \\
\hline & & More than 27 (heavy users) & 7 & 17 & 24 \\
\hline & & Totals & 49 & 51 & 100 \\
\hline
\end{tabular}

\section{Is there an association between level of use of recordings and performance?}

Bearing in mind that there is unlikely to be a simple relationship between recording use and performance due to the many other factors that affect performance, we nevertheless found it 
illuminating to compare the levels of usage by successful and unsuccessful students. We will again only discuss the mathematics course results here as the numbers in the quantitative literacy course are too small to draw conclusions.

By dividing students according to whether they passed or failed the course, some revealing observations regarding recording usage were made (statistical analysis was not appropriate here as the failing group was small $-11 \%$ of all students). None of the students who failed the course outright (i.e., students whose course result was too low for them to be offered a supplementary exam) were users. Students who passed the course viewed, on average, 2.7 times as many recordings as those who did not pass the course. The average number of unique views among the failing group was 11 (4.6 for those who failed outright, 16.8 for those who were offered a supplementary exam), whereas that for the passing group was 30 .

We also examined the recording use of students who performed better than average, i.e., those whose performance placed them in the top half of the class, and found the following associations. Students whose performance placed them in the top half of the class were almost twice as likely as those in the bottom half to be lecture recording users (Table 2a); similarly, above-average performers are 2.3 times as likely as below-average performers to be heavy users of lecture recordings (Table $2 \mathrm{~b}$ ). Chi-squared testing showed that these associations are significant ( $p=0.014$ and $p=0.025$ respectively). These results all suggest that there is an association between greater use of recordings and better performance in the course.

Table 2a: Numbers of users in the mathematics course categorised according to level of use of lecture recordings and level of performance in the course

\begin{tabular}{|l|c|c|c|}
\hline & $\mathbf{1 0}$ views or fewer & More than $\mathbf{1 0}$ views & Totals \\
\hline Course result $<$ median & 33 & 15 & 48 \\
\hline Course result $\geq$ median & 22 & 28 & 50 \\
\hline Totals & 55 & 43 & 98 \\
\hline
\end{tabular}

Table 2b: Numbers of users in the mathematics course categorised according to level of use of lecture recordings and level of performance in the course

\begin{tabular}{|l|c|c|c|}
\hline & $\mathbf{2 7}$ views or fewer & More than 27 views & Totals \\
\hline Course result < median & 41 & 7 & 48 \\
\hline Course result $\geq$ median & 33 & 17 & 50 \\
\hline Totals & 74 & 24 & 98 \\
\hline
\end{tabular}

\section{When are recordings used?}

To get a sense of how students' use of the recordings was distributed over time throughout the semester, we made use of the complete set of viewing data supplied by the learning management 
system, rather than unique views. This different way of using the viewing data was chosen because in this case it was relevant to include the possibility that students view the same lecture multiple times. The frequency and timing of views is illustrated in Figure 9.

The data shown in Figure 9 supports what Nordmann and McGeorge $(2018,20)$ describe as "bingeing the box-set", that is, there was increased viewing activity in the periods just before assessments, with the highest number of views by mathematics students occurring in the week before the final exam, 85 per cent of them being by heavy users.
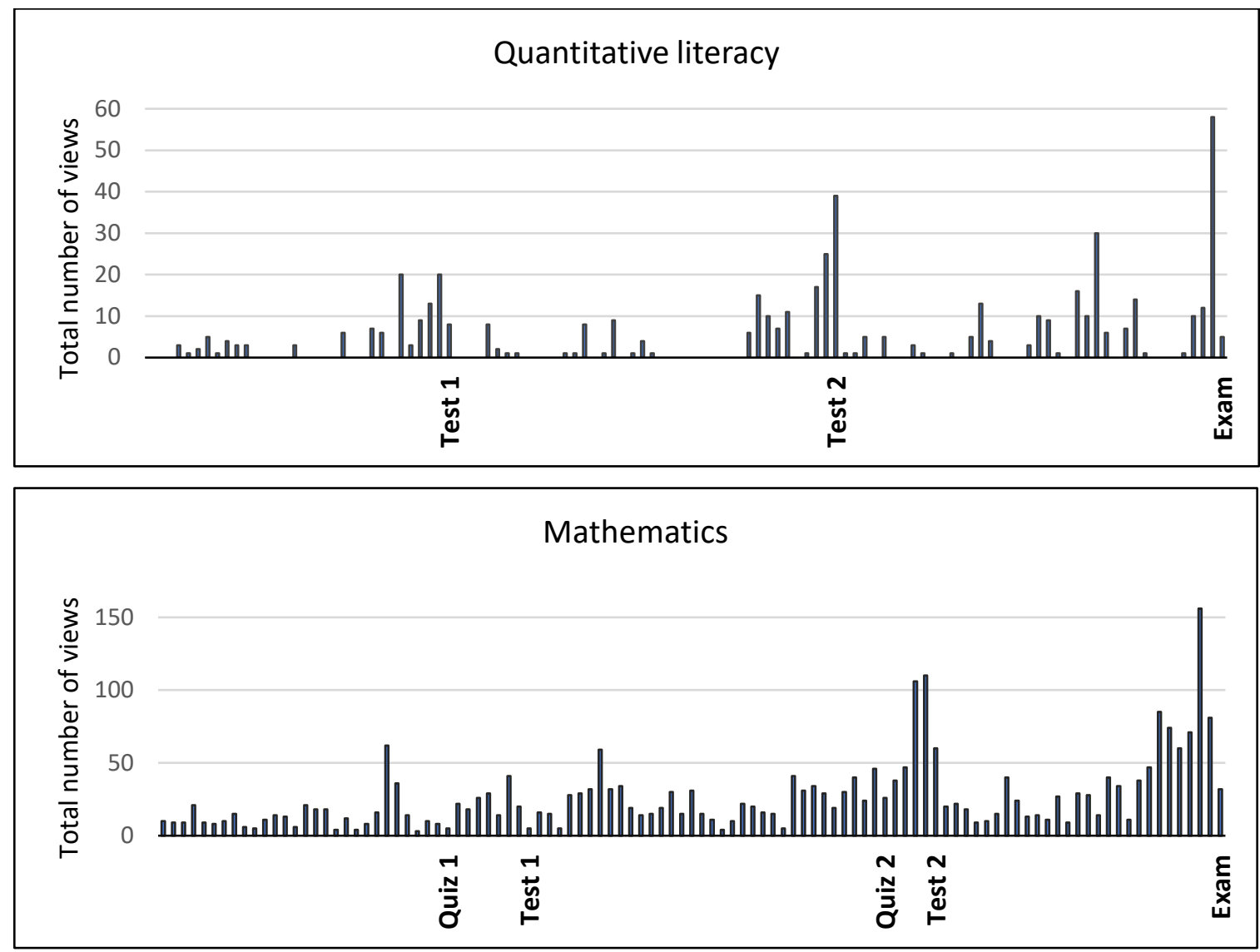

Figure 9: The frequency and timing of all (non-unique) lecture recording views throughout the semester

We had anticipated that perhaps the heavy users would be distributing their viewing more evenly across the semester, but even among these students we noted a range of viewing patterns: from a number of students whose non-unique views were concentrated in only a few weeks of the semester to two students who seemed to use the recordings consistently throughout the semester and accessed recordings in all weeks of the semester except one.

\section{LIMITATIONS OF THE STUDY}

There were several sources of difficulty in this study related to the reliability of the data that limits the confidence with which we can make claims. It is useful to describe these in some 
detail, so that other researchers planning similar studies can be aware of the possible pitfalls and try to design their studies to avoid them.

The first problem that emerged was that we did not anticipate that there would be such low levels of usage of the recordings by the quantitative literacy students. This severely limited our ability to use the data from this course for answering questions about the reasons for and manner of use of lecture recordings.

The second problem was with the questionnaire data. Many students did not follow the instructions on the form, for example, failing to rank their three main reasons for use, or answering questions in part of the survey that did not apply to them. We would recommend that, if using questionnaires, especially with first-year students, researchers use a simple design with uniform types of questions, and no conditional branching. Since there was considerable evidence that students did not read the instructions in the questionnaire carefully, it also raises the question of how well they understood the questions and how reliable their answers were.

Thirdly, our results were probably affected by the fact that the one third of the students who did not fill in a questionnaire were absent from lectures and tutorials, meaning that many of them could have been students whose attendance was generally lower. These students could thus well have been heavier users of the recordings, making their responses to questions about their usage important for an unbiased sample.

A fourth difficulty related to the attendance data. In the literature (O'Callaghan et al. 2017, 405 ) it was pointed out that many studies depended too heavily on students' self-reported data about attendance. We hoped that using attendance registers and card-scanning records would provide a more reliable measure, but this data still proved to be not without problems. We know that students sometimes sign for each other in lectures and there is a chance that card scanning does not always provide accurate data. For example, a student who according to the scanner data apparently attended no lectures claimed in the questionnaire to have attended most lectures.

Lastly, as mentioned before, the number of different lecture recordings accessed by a student (unique views) provides only an indication of their level of activity with regard to recordings, but is not an accurate measure of the number of recordings they actually used, or the extent of that use. Because of these problems with the reliability of the data, attempting to triangulate data from student surveys, the learning management system and attendance records proved more problematic than anticipated.

\section{DISCUSSION}

Our study confirms what other researchers have found, namely that students value the availability of recordings and that the extent of use is context dependent. Students in both 
courses were positive about the availability of recordings, but those in the quantitative literacy course used them much less than the mathematics students. The relative unpopularity of the lecture recordings in the quantitative literacy course may also have been a result of the fact that these students had access to the Powerpoint presentations, which they may have found quicker and easier to navigate in order to search for specific sections. Data provided by the learning management system indicates that, on average, the Powerpoint presentation accompanying each lecture was accessed 61 non-unique times, compared with the 16 non-unique views per lecture recording. This is exemplified by one student's stated reason for not using the recordings: "I haven't went to all the lectures but I have attended the majority of them and I find the Powerpoint presentations really helpful". What this does show is that students need and use online resources of various kinds in addition to face-to-face lectures.

It is also possible that the students in the quantitative literacy course, being in their first year at university, were less aware of the educational value of the video recordings than the mathematics students (perhaps shown by the increase in lecture recording use in the quantitative literacy course after the survey, when students were made aware of them). Less frequent use of recordings could also be because the nature of the lecture delivery as "lecture-workshops" may make the recordings less useful. Also, the law students in the quantitative literacy course displayed, in general, a higher language proficiency, which may explain why they made less use of recordings.

The students' responses to our questionnaire suggested that availability of recordings may encourage them to miss lectures, but we could not find any concrete evidence that attendance is negatively affected by the recordings, in the sense that there was no association between extent of recording use and attendance. This result is reassuring to lecturers who fear that students will prefer to watch the recordings rather than attending lectures. We concur with Nordmann and McGeorge $(2018,6)$ that "rather than ask will lecture recordings reduce attendance, if that does occur ... then the question should rather be why and what can it tell us about our pedagogy".

Contrary to the finding stated in the literature review quoted above, that students generally more often use recordings to review material than to make up for missed lectures, about half of the users in our study reported that their main reason for using recordings was to make up for missed lectures, in which case they tended to watch the entire recording.

Our finding that in both courses students tended to access the recordings most frequently in the periods immediately before assessments was in agreement with the findings of other studies in the literature (for example, Collier-Reed, Case and Stott 2013, 336; Chen and Lin $2012,13)$. This tendency to cram rather than to distribute learning evenly across the semester 
is generally thought to lead to superficial learning (Dunlosky et al. 2013, 35) but may also be pragmatic behaviour by students who have many competing demands on their study time. Chen and Lin $(2012,13)$ suggest that the increased use of lecture recordings just before assessments does not necessarily reflect bad learning practices, but may show that as students become serious about their learning closer to assessments, they become aware of gaps in their knowledge and use the lecture recordings to complement their learning, in the same way they would use text books or other materials.

For the students in the mathematics course we found a highly significant association between lower academic literacy scores and higher lecture recording use, which shows that provision of recordings is beneficial for students who are less well-prepared to deal with academic language in English. This result is consistent with the greater recording use by second language speakers reported in other studies mentioned in the literature review above, but provides quantitative evidence based on a more objective measure than student self-reported data. This result provides strong motivation for continued widespread provision of recordings in higher education settings where many students are not English first-language speakers. It is fortunate that an educational innovation that is so popular with students can also be one that particularly benefits those who are at a disadvantage due to language difficulties.

For the students in the mathematics course we also found a significant association between lecture recording use and performance. This association is not necessarily causal, but presumably indicates that students who are better able to regulate their own learning by making appropriate use of available resources, including recordings, are more likely to succeed.

We assert that an understanding of how students use lecture recordings can inform the process by which lecturers might assist first-year students in particular to become more effective users of the recordings. We conclude our discussion by adding some suggestions for classroom practice that have emerged as a result of this study to those made in previous studies. First, we suggest that lecturers alert new students to the existence of lecture recordings early in the semester. Thereafter the potential benefits of lecture recordings could repeatedly be made explicit through recommendations such as those made by Nordmann and McGeorge $(2018,20)$, whereby lecture recordings are promoted as learning resources, not as substitutes for live lectures, and students are encouraged to use recordings throughout the semester (not just before an exam) in a selective way that fosters deep learning.

Collier-Reed, Case and Stott $(2013,338)$ suggest that the existence of lecture recordings has the potential to change students' approach to engaging in class - students can become more selective about the attention that is paid to note-taking in order to engage more actively in the material being covered in the lecture. We suggest that students can be assisted in adopting this 
practice by lecturers indicating points in the lecture where complex concepts or ways of reasoning are to be discussed. Not only is this good teaching practice, but it will facilitate the efficient reference to the point in the lecture recording for the purpose of making notes. Students could be advised to note the time so that the corresponding point in the lecture recording can be found easily later.

The final practical suggestion comes from a student who recognised the usefulness of the lecture recordings but suggested that "If lecture videos had headings describing the section it is covering that would be great". Evidence from our study showed that there were students who accessed the same lecture, on average, up to six times and this could be because they were searching for particular topics. In order to facilitate the use of lecture recordings as a learning resource, the identification of the appropriate lecture recording can be made more efficient for students by lecturers having an initial slide (or note on the chalkboard if slides are not used) that features the lecture number and topic. This will be captured by the recording system and will obviate the need for students to access multiple recordings when searching for a certain topic.

\section{CONCLUSIONS}

The results of any one study such as this one, especially on relatively small numbers of students, cannot be widely generalised across contexts, because student behaviour regarding lecture recordings is so dependent on many factors which differ in different courses and for different cohorts of students. However, generalisation to similar courses for similar students in the South African higher education setting can be done, and will be useful for informing the lecturers of those courses. An important reason for lecturers to be aware of how students use recordings is so that they can understand what to recommend to students regarding the most effective use of the recordings as a supplementary learning resource.

Our study confirms that students value the availability of recordings and think that it improves the quality of their learning. This observation is important for lecturers in higher education to recognise, and provides justification for continuation and expansion of the effort and expense that institutions devote to making lecture recordings available.

We found no concrete evidence that attendance is negatively affected by the availability of recordings. This result can be used to reassure lecturers who fear that students will prefer to watch the recordings rather than attending lectures, and can be used to motivate lecturers who are reluctant to make use of recordings in their courses.

For the students in the mathematics course we found a highly significant association between lower academic literacy scores and higher lecture recording use, which shows that 
provision of recordings is beneficial for students who are less well-prepared to deal with academic language in English. This result provides strong motivation for continued widespread provision of recordings in higher education settings where many students are not English firstlanguage speakers, particularly if further research shows that this result can be replicated for other cohorts of students in different disciplines. This is especially pertinent in South Africa, where three quarters of the students in higher education are black African (Council on Higher Education 2019, 3), the great majority of whom would not have English as their home language.

We found a significant association between lecture recording use and performance for the students in the mathematics course. This suggests that students who are better able to regulate their own learning by making appropriate use of available resources are more likely to succeed. The implication of this for teaching and learning practice is that lecturers need to explicitly encourage students to make regular use of lecture recordings as a supplementary study aid and provide pointers to how to do so most effectively.

We have seen in our study that students perceive that the availability of lecture recordings has improved their learning. By being aware of how students, especially those who are academically immature, use the recordings, it is possible for lecturers to implement changes in their own classroom practice that will enable students to make better use of these resources and enhance student learning.

\section{ACKNOWLEDGEMENTS}

We would like to thank the students who participated in our survey and the staff of the Centre for Innovation in Learning and Teaching at our university who provided us with the data collected by the learning management system. We are also grateful to the Centre for Educational Testing for Access and Placement for providing the NBT Academic Literacy Test data.

\section{REFERENCES}

Chen, J. and T. F. Lin. 2012. Do supplemental online recorded lectures help students learn microeconomics? International Review of Economics Education 11(1): 6-15. http://citeseerx.ist. psu.edu/viewdoc/download?doi=10.1.1.676.1487\&rep=rep1\&type $=$ pdf\#page $=6$

Collier-Reed, B. I., J. M. Case and A. Stott. 2013. The influence of podcasting on student learning: A case study across two courses. European Journal of Engineering Education 38(3): 329-339. https://doi.org/10.1080/03043797.2013.786026

Council on Higher Education. 2019. Vital Stats: Public Higher Education 2017. Pretoria. https://www.che.ac.za/media_and_publications/monitoring-and-evaluation/vitalstats-publichigher-education-2017

Cummins, J. 1999. BICS and CALP: Clarifying the distinction. https://files.eric.ed.gov/ fulltext/ED438551.pdf 
Danielson, J., V. Preast, H. Bender and L. Hassall. 2014. Is the effectiveness of lecture capture related to teaching approach or content type? Computers \& Education 72: 121-131. https://dx.doi.org/ 10.1016/j.compedu.2013.10.016

Draper, M. J., S. Gibbon and J. Thomas. 2018. Lecture recording: A new norm. The Law Teacher 52(3): 316-334. https://doi.org/10.1080/03069400.2018.1450598

Dunlosky, J., K. A. Rawson, E. J. Marsh, M. J. Nathan and D. T. Willingham. 2013. Improving students' learning with effective learning techniques: Promising directions from cognitive and educational psychology. Psychological Science in the Public Interest 14(1): 4-58. https://doi.org/ $10.1177 \% 2 \mathrm{~F} 1529100612453266$

Griesel, H. 2006. Access and entry level benchmarks, the National Benchmark Tests Project. Pretoria: Higher Education South Africa. http://www.cetap.uct.ac.za/sites/default/files/image_tool/images/ 216/2006_HESA_Access\%20and\%20Entry\%20Level\%20Benchmarks.pdf

Karnad, A. 2013. Student use of recorded lectures: A report reviewing recent research into the use of lecture capture technology in higher education, and its impact on teaching methods and attendance. London School of Economics and Political Science, London, UK. http://eprints. lse.ac.uk/50929/1/Karnad_Student_use_recorded_2013_author.pdf

Kay, R. H. 2012. Exploring the use of video podcasts in education: A comprehensive review of the literature. Computers in Human Behavior 28: 820-831. https://doi.org/10.1016/j.chb.2012.01.011

Mallinson, D. and Z. Baumann. 2015. Lights, camera, learn: Understanding the role of lecture capture in undergraduate education. PS: Political Science \& Politics 48(3): 478-482. https://doi.org/ $10.1017 / \mathrm{s} 1049096515000281$

Nordmann, E., C. Calder, P. Bishop, A. Irwin and D. Comber. 2019. Turn up, tune in, don't drop out: The relationship between lecture attendance, use of lecture recordings, and achievement at different levels of study. Higher Education 77: 1065-1084. https://doi.org/10.1007/s10734-0180320-8

Nordmann, E. and P. McGeorge. 2018. Lecture capture in higher education: Time to learn from the learners. Preprint. https://psyarxiv.com/ux29v

O'Callaghan, F. V., D. L. Neumann, L. Jones and P. A. Creed. 2017. The use of lecture recordings in higher education: A review of institutional, student and lecturer issues. Educational Information Technology 22: 399-415. https://link.springer.com/article/10.1007\%2Fs10639-015-9451-z

Witthaus, G. R. and C. L. Robinson. 2015. Lecture capture literature review: A review of the literature from 2012-2015. Loughborough: Loughborough University. https://dspace.lboro.ac.uk/dspacejspui/bitstream/2134/25712/3/Witthaus_Lecture 